\title{
The Inspiration of Light and Shadow on Design
}

\author{
TANG Hai-yan ${ }^{1}$, QUE Yi ${ }^{1}$, ZHANG Zhi-wei ${ }^{1}$, and LI Qi ${ }^{1}$ \\ ${ }^{1}$ City College of Science Technology, Chongqing University, 402167, China
}

\begin{abstract}
Shadow as a design element applied to architectural and landscape design, can embellish, foil, and even enhance the subject. The shadow can also make the design works full of vitality and characteristic. Based on the actual cases, this article analyses the effect of shadow on architecture and landscape, and reveals the special effect producing by shadow. The effects include breaking the visual limitation, enhancing the connotation and artistic conception of the design. Shadow can give people an unexpected artistic appeal and spiritual shock. And bring much richer experience and even much more deep thinking to people.
\end{abstract}

In the construction of space, light can not only build spatial shape, redirect sight, make people experience the beauty of time, but also, the effect produced by shadow and light can intensify the theme, make observers experience the artistic conception within, therefore having resonance, causing thinking on the observed object, and realizing the objectives of deepening the main body, strengthening the theme and highlighting the features.

\section{The application of light and shadow in religious architecture and scenario}

In ancient times, whether the rulers in the east or in the west, they took full advantage of religion to govern their subjects. Besides using language to publicize the doctrine of religion, they also used the silent language of religious architecture, combined the use of light to form visual contrast and led people to "abandon the darkness for light", so that people's mind would calm down. That's why people enjoy going to religious architectures to seek mental peace.

\subsection{To set off the atmosphere via the light and shadow of a particular time}

In western religious architecture, designers were very good at using light and shadow to produce a religious atmosphere, produce mystery, and strengthen the influence of the "divine rights of kings". Take the Abu Simbel Temples of Egypt for example. In design and construction, it uses the most advanced astronomic, geological and mathematical knowledge of that time, so that on February $22^{\text {nd }}$ and October $22^{\text {nd }}$ of each year, the light will pass the 60-meters long yongdao (paved path leading to a main hall or a tomb), and shine directly over the sculpture of Ramesses II (see figure 1), which is located at the innermost of the temple, while the god of darkness, Ptah, will always remain in the darkness, astonishing people greatly. Such environment strengthens people's feelings of reverence and esteem for Ramesses II, and they call him "favorite of the sun".

\subsection{Use dark-light contrast to increase sense of mystery}

The darkness can arouse people's fear. Everyone yearns for light and evades darkness. Church of Light purposefully offers a dark environment, which will arouse people sense of disturbance. The only place that can alleviate people's fear is the huge cross of light on the wall (figure 2). In the dark environment which causes people's disturbances, the cross of light represents light and hope. Under such strong contrast, the cross of light is of enormous appeal to people.

Thus, we can feel the unique application of architectural skills of Tadao Ando in the design of the Church of Light. He used simple architectural languages (darkness, closeness, simple concrete, cross of light) to express the collision and contrast between darkness and light, so as to inspire people's emotional resonance and demonstrate special artistic charm.

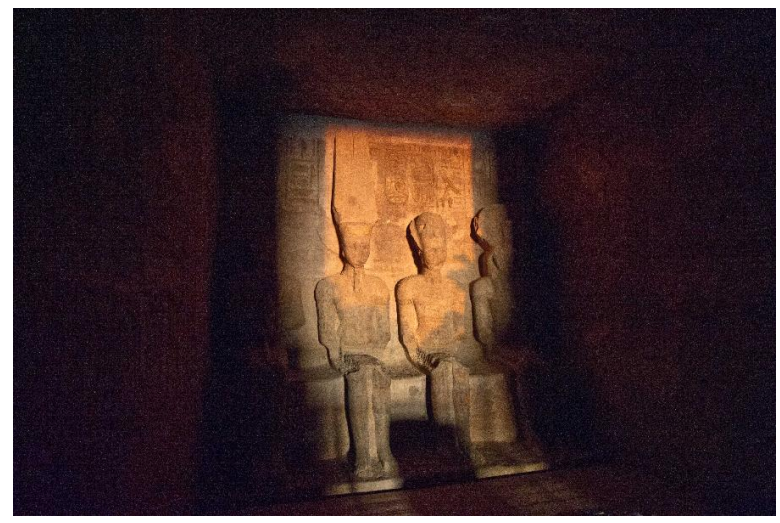

Figure 1 The sun shines over the sculpture of Ramesses II 


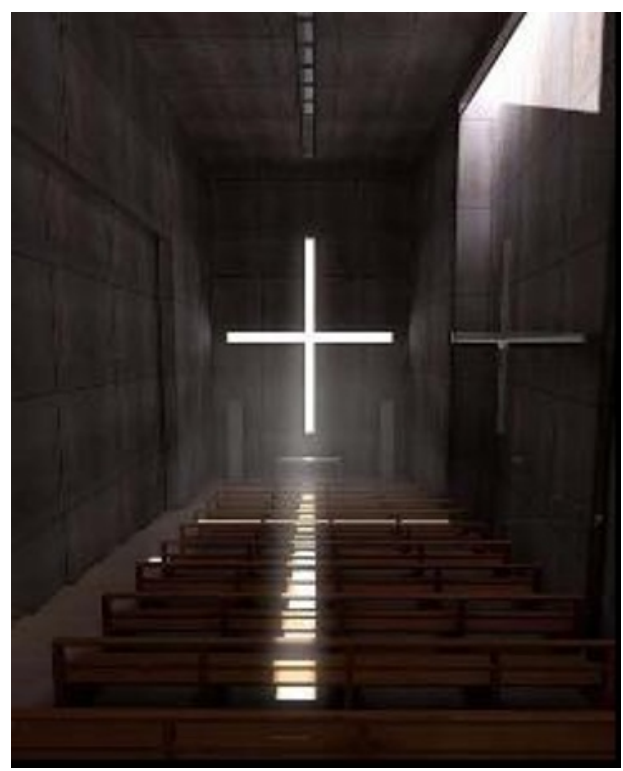

Figure 2 The huge "cross of light" in Church of Light

\subsection{To enhance the effect of light via colorful glass windows}

Light has always played an important role in religious architecture. People believe that the light shining from the colorful glass window to the church is a kind of divine light. It reminds us the spirit of God. Whether it's the Roman church or Gothic church, they all embody the unity of aesthetics and theology via the light. The "bible of the illiterate" - colorful glass window, best represents the wonderful light, resembling light from heaven. of the church

To holy adoption of light is also one of the artistic features of La Chapelle de Ronchamp, designed by Le Corbusier (Figure 4, Figure 5). "Glory hides at each corner" of the church. Via the mysterious atmosphere formed by the ornamental perforated windows on the wall and the delicate "cavern" of light and shadow, the designer allows people to experience the reverence and esteem towards light of God.

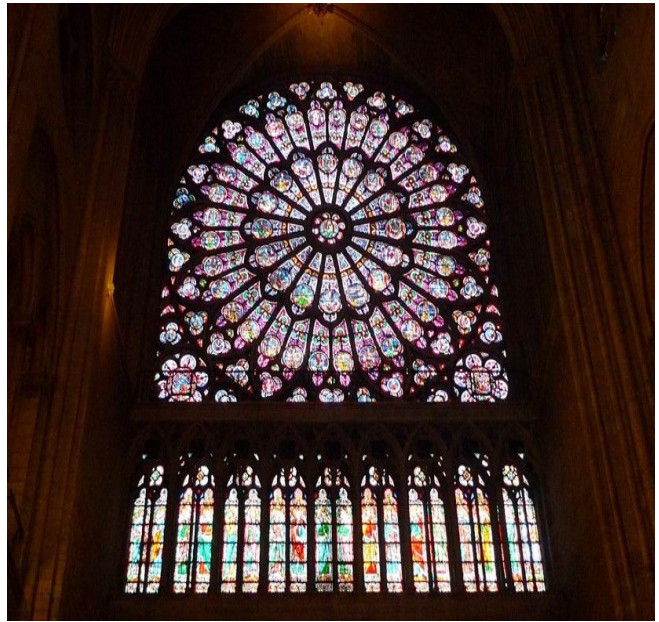

Figure 3 The colorful glass windows

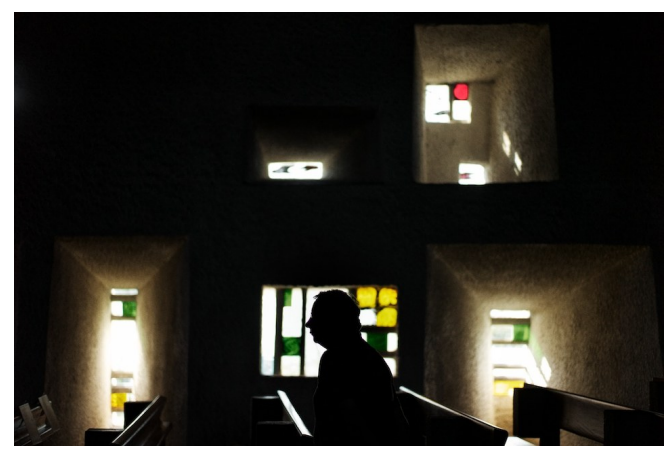

Figure 4 The followers pray under the mottled

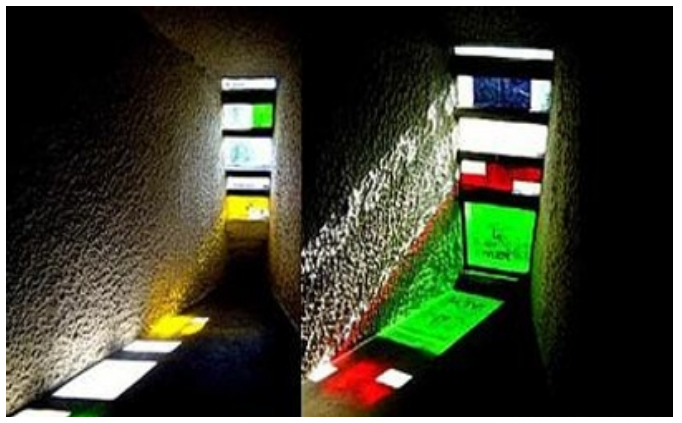

Figure 5 The light casts into the church via the colorful glass windows

\section{The application of light and shadow in architecture groups}

\subsection{To take advantage of the rising sun and the setting sun to add color to the architecture groups}

The light of the nature can add color to the architecture or landscape work. The key is to process the correlative location between the architecture and the sun. This is particularly important. The tomb of emperors, the spatial sequence which expands along the east-west line, will achieve unique lighting effects. For example, the spatial sequence formed by the Giza pyramid groups and their yongdao (paved path leading to a main hall or a tomb). Some memorial architecture landscapes borrow the sunlight to produce special effects, via special orientation and arrangement. For example, the landscape whose main axles are east-west direction, will form special effect by taking advantage of the light, in the first rays of the morning sun or the glow of the setting sun. The tomb of Genghis Khan and the pyramid of ancient Egypt are landscapes of such type. The three pyramids of Giza pyramid group are placed at the west of the yongdao (paved path leading to a main hall or a tomb) that people use to pay respect. The ancient Egyptians believe that the Pharaoh will die at the west and resurge from the east. So the Pharaoh who passed away should stay in the west like the setting sun. Such concepts and layout pattern achieve unexpected, astonishing artistic effects. When the magnificent and simple-shaped pyramids and the sun which gives out afterglow fall before people's eyes 
at the same time, people will feel the greatness and eternity of such image.

\subsection{Establish the orientation of the architecture skillfully according to the orientation of the sun}

Most important architectures of China will adopt of the orientation of facing the south. The builders will make the architecture or the façade of the architecture groups face the south. This is because China is located in the northern latitude regions, facing the south will enable the architecture to gain sufficient sunlight. The light and shadow produced can effectively foil the mass of the architecture, thus the features and style of the architecture or architecture groups can be best demonstrated.

\section{The application of light and shadow in landscapes}

\subsection{To use light and shadow to create special artistic conception}

In Chinese parks, the shadow of the moon, the shadow of the flowers, and the shadow of the bamboo are used to be the tool to indicate light, making people fall into a reverie. The modern style Suzhou Museum is not only a miracle of architectural design, but also a manifestation of humanitarian care and national affection. The major courtyard of the new museum is a delicately built creative water \& mountain garden. The artificial hill made of stone pieces under the northern wall of the water \& mountain garden is a unique invention of Mr. Bei. This unique water \& mountain landscape that "regards the wall as the paper and regards stone as the painting" presents clear outline and silhouette effect. When you look at it, you will feel that it is connected to the Humble Administrator's Garden. The view of the new garden and the old garden integrate with each other subtly. Mr. Bei used light and shadow to create the poetic image of water and ink enjoyable scenery paintings of "Mi's water and mountain" of the Song Dynasty.

\subsection{To increase the interestingness of the landscape via light and shadow}

Three Pools Mirroring the Moon, called the "No.1 scenic spot of West Lake", is a typical success case of ancient people's using light and shadow to build scenery. It is recorded in West Lake Records that: "the moonlight is reflected on the water, dividing the pagoda into three. That's how Three Pools Mirroring the Moon comes into existence." During a bright night, paste the hole with thin paper, light a candle in the pagoda, the candle light passes through the pagoda. At this time, the pagoda shadow, cloud shadow and moon shadow integrate into one, forming a splendid scene of the candle light's, moon light's, and lake light's adding radiance and beauty to each other. The shape of the hole is reflected onto the lake, presenting many moons. It is difficult to distinguish the shadow of the real moon and the fake moon. This night view is very fascinating, that's how it derives its name "Three Pools Mirroring the Moon".

\subsection{To create different landscape effects via the change of light and shadow.}

Plaza del Bebedero los Caballosis a work of Barragan. The use of sunshine can be regarded as the finishing touch of this work. It brings the sunshine and air in nature into our sight and life, and the sunshine and air interlace with the strong colored walls, producing a miraculous effect. Under the cover and reflection of the tree shadows, a pure and simple white wall, at the end of the pool of Plaza del Bebedero Caballos, begins to have vivid expressions. The falling shadow on the ground, the falling shadow on the wall, and the shadow in the water form a three dimensional coordinate system of light. Within 1 day, with the change of light, the coordinate system moves and rotates slowly, like a kind of blurred dancing. This is the conversation between the architecture and the nature. The shady tree shadow on the white wall seems to leave a poetic picture scroll on the architecture, via the sunshine, the air and the plants. The light, color, space, wall, water, ground, and plants interlace miraculously, giving people a dreamy feeling and making people integrating into the poetic space.

\section{Conclusion}

The visual effect caused by the light and shadow's participation in the design exceeds the general limitation of visual sense and enables people to appreciate another kind of psychological experience. So to build a reasonable light and shadow space can vividly strengthen the theme of the architecture and landscape. It is a kind of special language expression form and a kind of method that can connect sense organs, join consciousness and create poetic images. It will effectively provoke people's mind, therefore making people observe the artistic conception that the architecture and the landscape intend to express in an in-depth manner. This is precisely the basic needs of the architecture and landscape design - to meet people's physiological and psychological needs.

When architect uses the light or shadow of the sun or the moon skillfully to build special scenes, an eternal artistic effect of "human and nature integrate into one" will be created, namely to apply the endless power of the nature in architecture or landscape design can add color to natural or artificial landscape, and can endow them mysterious and holy temperament and features, because no great artificial article can compete with the sun, the moon and the stars. Such principles will enlighten us to pay attention to and skillfully use eternal factors such as the sun, the moon, and the stars and integrate them into the work, therefore deepening 
the design theme. Tao Te Ching tells us that "the to be or not to be grow out of one another", revealing the relationship between the tangible and the intangible, so in design, we should not only apply "tangible" light, but also should attach importance to the application of the effect of "intangible shadow".

\section{References}

1. Zeng Yan, Luo Liting. The Light and Shadow's Interpretation of Garden Space of Scholars of the South of the Yangtze River [J]. Science \& Technology Association Forum. March, 2007

2. Huang Changhua. Architecture's Light Environment Art [J]. Fujian Architecture. October, 2007
3. Ma Xinfan. An Analysis of the Light's and Shadow's Psychological Effect in Virtual Space [J]. Art \& Design. August, 2009

4. Zhao Xiangwei. The Light Environment Intention of China's Traditional Garden Space [J]. China Building Design \& Decoration. May, 2011

5. CHEN Si ,QIN Hua.On Application of Light and Shadow in Landscape Space[J]. Journal of Southwest China Normal University (Natural Science Edition). Jan,2017

6. Zhang Xuedan, Cheng Huaqing, The Aesthetics and Application of Light and Shadow in Landscape Architecture (J) Modern Horticulture.2017(17) 